\title{
Creating business intelligence from course management systems
}

\author{
Liezl van Dyk, Centre for Teaching and Learning, University of Stellenbosch, \\ Matieland,South Africa \\ Pieter Conradie, Department of Industrial and Systems Engineering, University of \\ Pretoria, Pretoria, South Africa
}

Purpose - This article seeks to address the interface between individual learning facilitators that use course management systems (CMS) data to support decision-making and course design and institutional infrastructure providers that are responsible for institutional business intelligence.

Design/methodology/approach - The design of a data warehouse is proposed that draw data from institutional transactional systems to provide decision support to individual action researchers. A prototype data warehouse is built to evaluate by means of a case study the usefulness validity of analyses performed.

Findings - Many facilitators of learning draw manually the same type of queries from CMS data for purposes of action research. On the other hand, more and more HEI infrastructure providers create data warehouses to support many kinds of decisionmaking. It is possible and valuable to follow a business intelligence approach to facilitate the queries drawn by individual action researchers from course management systems (CMSs).

Practical implications - The expectation exists that as the technology on which CMSs, as well as business intelligence tools are built evolves, the creation of full-scale business intelligence will become more feasible and scalable.

Originality/value - This article addresses the gap between individual action researchers that use CMS data to support decision making and course design, on the one hand, and institutional infrastructure providers that are responsible for institutional business intelligence on the other hand. Research questions are asked and addressed and processes are designed to manage business measurements consistently.

\section{Introduction}

The streamlining of business practices and the more efficient use of information technology are necessary for higher education institutions (HEIs) to cope with pressures 
to improve productivity. To accomplish this, HEIs rely on transactional information systems such as the financial management system (FMS), the human resource management systems (HRMS), student information system (SIS), as well as course management system (CMS). Each time a student register for a course, modify an address or settle an account, a transaction is performed by the SIS or enterprise resource planning (ERP) system. Each time a lecturer upload results to the SIS a transaction is performed. Each time a lecturer or student logs into the CMS, participates in online discussions, completes an electronic quiz or reads an electronic document, a transaction is performed. With each transaction performed, data are captured and stored by the transactional system. As a result loads of data are created, which is often only archived for record keeping purposes and not used to support decision-making.

The business intelligence guru, Ralph Kimball defines business intelligence as "a generic term to describe leveraging the organization's information assets for making better business decisions” (Kimball and Ross, 2002). Business intelligence entails the gathering of data from internal and external data sources, as well as the storing and analysis thereof to make it accessible to assist in better decision making (Wikipedia, 2006). For the design and building of HEI data warehouses a top down approach is followed by institutional infrastructure providers to equip decision makers with information to support decision-making. Individual learning facilitators - on the other hand - focus on their own individual area of interest when analyzing data for purposes of action research. Zuber-Skerrit (1992) describes action research as "a critical enquiry by academics themselves [rather than expert educational researchers] into their own teaching practice, into problems of student learning and into curriculum problems”. Action researchers increasingly draw upon data provided by CMSs to analyze the effectiveness of their teaching practice.

\section{Purpose}

This article addresses the gap between individual action researchers that use CMS data to support decision making and course design, on the one hand, and institutional infrastructure providers that are responsible for institutional business intelligence on the other hand. The following research questions are asked:RQ1. What is the structure and content of a typical HE business intelligence framework? RQ2. What are typical ad hoc analyses performed by action researchers? $R Q 3$. What more can be gained if a business intelligence approach is followed? How can these queries be standardized to enhance business intelligence for HEIs? RQ4. What is the usefulness of these measurements?

\section{Methodology}

The first two research questions are addressed by a survey of literature. To address research questions 3 and 4 a prototype data mart is designed that draw upon data from existing CMSs and SISs to enable the queries typically performed by individual action 
researchers. Measures for 47 undergraduate courses presented to Industrial Engineering students during 2005 are investigated to discuss the usefulness of these measures.

\section{Business intelligence within context of a higher education institution}

Table I shows a business intelligence framework for a typical HEI. Data are created and stored whenever a transaction is performed by a transactional source system. These systems - as indicated on the right hand side of Figure $\mathbf{1}$ - serve as sources from which data are extracted, transformed and loaded (ETL) into the data warehouse. From the data warehouse ad hoc queries can be drawn by users to support decision making as indicated on the right hand side of this figure. Ultimately, standard processes are designed to manage business measurements consistently.

An increasing number of higher education institutions (HEIs) are developing institutional data warehouses to leverage information assets. Educause maintains a directory of data warehouses in higher education as part of the activities of the Educause decision support and data warehousing constituent group (Heise, 2005). Since the first contribution was made to this directory on 16 November 2000, the number of participating HEIs has grown to about 100 institutions, primarily from the USA, but also from Europe. This is not an exhaustive directory of data warehouses in higher education, but provides an overview of the typical source system, technology to extract, transform and load data (ETL), data warehouse architecture and business areas addressed by these data warehouses. An overview follows, structured according the framework shown in Figure 1.

\section{Source systems}

Systems that are typically used as input to these HE data warehouses are shown on the left hand side of the business intelligence framework (Figure 1). Whitten (2004) describes an ERP as "a fully integrated collection of information systems that span most basic business functions required by a major corporation. These systems include accounting and finance, human resources, sales and procurement, inventory management, production planning and control”. The concept of an ERP system is not recognized by all HEIs. The only off the shelf ERP system that is mentioned on the Educause directory (Heise, 2005) is PeopleSoft. Nevertheless, all HEIs have source systems to manage transactions that are typically being performed by an ERP system. Examples of such transactions relate to human resource management, financial management, accommodation and facilities.

A student information system (SIS) is defined by Gartner's e-learning glossary (Lundy and Harris, 2001) as “ . ... the system used to enrol and register students, track curricula, courses and students. Transcripts, administrative details of courses taken, progress towards a degree and grades are typically included". All HEIs have some form of student information system (SIS). Most HE data warehouses extract data from student enrolment, 
student demographics, course management and particulars of prospective students. SISs often interface with some ERP functions. For example, student registration transactions (SIS) may be linked with fee payment transactions (ERP). Human resource management systems (HRMSs) become increasingly sophisticated to include skills- and performance management. Both the HRMS and the SIS normally interfaces with the financial management system (FMS).

No one of the HEIs that appears on the data warehouse directory indicated that CMS data are linked to the warehouse, despite the fact that all of these institutions make use of a CMS of some sort. Wikipedia (2005) describes a CMS as "a computer program that facilitates computerized learning or e-learning, especially by helping teachers and learners with course administration”. Learning management systems (LMS) and virtual learning environments (VLE) are listed as synonyms for CMS. VLE are used more regularly in the UK, whilst LMS is a term more popular in the United States (Akeroyd, 2005). In the HEI arena the two most dominant LMS products are WebCT and Blackboard. Both of these products started off as individual efforts by university staff to support the management of the teaching process through information technology and have grown into products that are being used on a large scale worldwide. These products are now owned by the same company, but still functions as two different products. According to Gartner's e-learning glossary (Lundy and Harris, 2001) a CMS have the following functionalities: registration capabilities; administration of curriculum and courses; student skills and records management; student interfaces to courseware; learning programs administration; external system application programming interfaces.

Many of the functions performed by a CMS can also be performed with conventional online tools. Students and lecturers can communicate by conventional e-mail or course content can be published on the web through conventional routes. These activities form part of the virtual classroom and may interface with the CMS or SIS. In very few cases the actual classroom can be eliminated. Despite the availability of this technology, faceto-face meetings and lectures are normally part of the teaching process, the so-called blended approach. There is also an interface between the actual classroom and other systems. For example, learning content that is discussed in the actual classroom is often published in the virtual classroom or it is published by the CMS. Results of tests that were written in the actual classroom environment can be published by the CMS. Such data may be extracted manually and loaded into the data warehouse. Data concerning HE calendars are typically not part of a specific transactional system. However, these data are often added manually to the data warehouse to enable analyses related to specific type of days, for example end of the month or weekends.

According to the higher education data warehouse directory the following tools are used by HEIs to extract, transform and load data into the data warehouse: Cobol, Sybase, Oracle data warehouse builder, Focus, MS Access, SAS, Informatica, Enterprise manager, Cognos decision stream or in-house developed tools. There is not a dominant type of technology used. The ETL approach and tool are determined by the available technology, as well as the technology on which source systems is based. 


\section{Queries and analyses}

Most of the HEIs listed in the data warehouse directory indicated that data concerning alumni are used to enable more effective and alumni-specific communication. This ability is especially useful when used in the identification of potential donors of funds. The approach and techniques used to accomplish business intelligence in this regard are in line with common customer relationship management (CRM) practices. CRM functions are typically part of the ERP system. An alumni-member is in principle a client of the HEI. Similarly, prospective students are potential clients. Many HEIs analyze data from institutional warehouses to determine which prospects are most likely to apply (Oracle, 2001). Personalized mailing campaigns are launched accordingly. Upon entering personalized identification codes a customized web page is opened, which reflects the interests of the prospective student. Prospective students progress through a standard set of admission procedures. A student registration mart may enable the tracking of activities concerning key dates, such as date of first application, date of test scores received or date of decision for final admission. Admission and enrolment managers are interested in how many applicants are at each stage in the pipeline (Kimball and Ross, 2002). This data mart can also provide decision support to managers of facilities and human resources.

\section{Typical action research analyses based on CMS data}

Most learning facilitators that use CMS data for purposes of action research, perform statistical correlation tests to determine the correlation between CMS activity per student and some other quantitative student attribute. CMS activity is typically measured as the total number of CMS transactions performed ("hits") by each student. This information is made available by the CMS in the form of student tracking reports. This information is derived from the original transaction data. Only the total number of transactions per student per course is published by these reports.

All action researchers under investigation, who measured the correlation between frequency of CMS hits and final examination results found a significant positive correlation (Alstete and Beutell, 2004; Bongey et al., 2005; Green et al., 2006). However, none could determine if this correlation should be attributed to the effect of CMSs on the quality of learning or to the effect of CMSs on course administration, or to the effect of CMSs on the facilitation of assessment events.

Learning styles are "characteristic cognitive, affective, and psychological behaviours that serve as relatively stable indicators of how learners perceive, interact with, and respond to the learning environment” (Felder and Spurlin, 2005). A few action researchers measured the correlation between learning styles and CMS activity (refer to Table I). 


\section{Business intelligence approach}

The value of a business intelligence approach in the first place is that more measures are available. The correlation of student performance and learning style with activity per CMS tool can be measured, which enable analyst to ascertain if the correlation should be attributed to the impact of CMSs on the quality of learning, or to the impact of CMSs on course administration, or to the impact of CMSs on the facilitation of assessment events. Second, a business intelligence approach enables the standardization of measures within an institution, which in itself contributes the usefulness thereof. In the section that follows a data warehouse design is proposed to not only enable measurement in terms of total CMS hits, but also in terms of hits per CMS tool. This enables the CMS facilitator to determine if the correlation between student success and CMS usage is an effect of higher quality teaching or the effect of CMS course administration or the effect of the fact the students are assessed within the CMS environment.

\section{Data warehouse}

The data warehouse is the place where transactional source data are specifically structured for query and analysis performance and ease of use. A data mart is a logical and physical subset of the data warehouse. A well-designed data mart is resilient when faced with unexpected user queries and is based on the most atomic (detailed or granular) data available. Each data mart contains at least one "fact" - a business performance measurement, typically numeric and additive, that is stored in a fact table. The meaning of a single row in a fact table is referred to as a grain. The fact table is the central table in a star scheme, characterized by a composite key consisting of foreign keys, linking the fact table to various dimension tables. According to the HE data warehouse directory, most HEIs make use of star schemes to design their data warehouse. To enable the measurement of effectiveness on online learning in terms of learning styles and performance, a data warehouse comprising of two data marts are proposed: A click stream data mart and an aggregate click stream data mart.

\section{Click stream data mart}

A click stream is the "composite body of actions taken by a user at a Web browser. The click stream exists tangibly in the form of web server logs, where each web server log record relates to a single page event” (Kimball and Ross, 2002). Each time a lecturer or student logs into the CMS, participates in online discussions, completes an electronic quiz or reads an electronic document, a transaction is performed. Transaction data are logged concerning the type and time of activity. The fact grain is the time and type of access log per student per module. The star scheme for this data mart is shown in Figure 2.

Five dimensions are included: 
1. Student dimension: All demographic information concerning student, including student records and grades.

2. Module dimension: For each module presented each year, data concerning term presented, lecturer and host department is part of this dimension.

3. Time of day dimension: For each minute of every day indicators related to opening of computer labs and official lecturing hours are included.

4. Date dimension: Based on the calendar of the HEI attributes associated with each date may include indicators concerning weekday (Monday, Tuesday, Wednesday etc.), academic day (e.g. holiday, test week, exam, lecture day) or special events (e.g. first day of new term).

5. Page dimension: Indicate for each page attributes related to that type of page, for example, whether it requires active engagement or whether it contains course content.

\section{Aggregate click stream data mart}

An aggregate is a physical row in a database - almost always created by summing other records in the database - for purposes of improving query performance (Kimball and Ross, 2002). By means of data mart data concerning the number of hits per student are aggregated. The design of the data mart allows that learning style indices that contained by the student dimension can be associated by means of the student key with the total number of hits per student (refer to Figure 3). Similarly, student results contained by the result dimension are associated with number of hits per student per type of tool. Queries to determine respectively the correlation between online behaviour and learning styles as well as online behaviour and student results can be drawn accordingly.

Table II is a map that shows from which transactional source systems data are extracted for purposes of this data warehouse.

Here, the ERP source system is not used. Data access may entail a simple activity as an ad hoc query or a complex sophisticated data mining application (Kimball and Ross, 2002). After data are extracted, transformed and loaded into the data warehouse, ad hoc queries or standardize performance measurement procedures can be executed.

\section{Case study}

WebCT has been used as CMS by the department of Industrial and Systems Engineering, since 2001. From 2005 all 47 undergraduate courses of this department have a WebCT presence. The purpose of this case study is to determine if the data warehouse design proposed here would yield more significant results. For purposes of this case study, Perl script and Visual Basic was used to extract, transform and load all access logs for all 47 undergraduate modules presented in 2005 to undergraduate industrial engineering students. The data warehouse is designed in MS Access. Data aggregation and correlation tests are performed in MATLAB 7.0. MS Excel is used for presentation purposes. 
The Felder index of learning styles (Felder and Silverman, 1988) was used for this study. Coffield et al. (2004) emphasize the important of determining the status of a learning style instrument and suggest that the following questions are asked: Is the instrument reliable? Is the instrument valid? How should tutors and managers be responding to the learning styles of their students? The first two questions concerning reliability and validity was considered by, amongst others, Felder and Spurlin (2005), Van Zwanenberg, Wilkonson and Anderson (2000) and Zwyno (2003). They conclude that this instrument is indeed reliable and valid as long as it is not used to label individual students, but rather to modify instruction to fit their labels. This article addresses the third question only partially. A business intelligence approach is suggested to equip learning facilitators with information to support decision-making and respond to learning styles of their students. However, pedagogical implications of this information are not explored.

The Felder instrument use 44 questions to measure learning styles along four dimensions:

1. Active-reflective;

2. Sensory-intuitive;

3. Visual-verbal; and

4. Sequentially-globally.

A total of 482 undergraduate engineering students completed the Felder ILS questionnaire for purposes of this study. The average learning style indices are shown in Table III together with results from similar studies amongst engineering students from other HEIs.

For each module a query can be drawn to measure the correlation and significance thereof ( $p<0.05$ indicate a significant correlation) between the frequency of CMS tool usage per student and the effectiveness of teaching in terms of student results and learning style index. The number of modules that show a significant correlation $(p<0.05)$ between CMS tool frequency and learning style or performance indices are listed in Table IV.

When a correlation test yield a $p$-value of less that 5 percent, it is generally accepted that the correlation between the sets of data is significant. Still, the chance of a type II error is 5 percent. Hence, one should be careful to base conclusions on the information provided by the previous tables. For the discussion that follows, only instances where more that 20 percent of the modules show a significant correlation are considered:

The "Homepage" should be viewed as a gate, rather that a tool. To access all other tools a student always need to enter the "Homepage" gate. Correlations found between "Homepage” use and learning styles or performance, are probably an effect of a correlation with another tool.

Reflective and sensing learners make more use of CMS. Reflective learners prefer to observe and think, before doing. Sensing learners prefer routine and facts. Engineering students are quite balanced as far as the active-reflective and sensing-intuitive learning 
dimensions are concerned. Since CMSs tend to complement the learning styles of reflective and sensing students, engineering educators could make an effort to address the learning needs of students that tend to learn actively and intuitively.

As far as final school score (M-score) is concerned, approximately the same number of correlation instances exist for "Homepage" and "Content" than in the case of semester mark and examination. The correlation in those instances is probably an effect of the students' intrinsic motivation, rather than the cause of an improved learning process. It seems as if the administrative elements of the CMS ("E-mail”, "Calendar" and "MyGrades) indeed contribute to the semester mark, notwithstanding the students' aptitude as portrait by the M-score. The assessment tools ("Assignments", "Discussions write" and "Quizzes") showed in most instances a significant correlation with semester mark, which confirms that it is the way in which a course is organized by the CMS that effect student performance and not necessarily the learning that take place.

In this article a business intelligence approach is suggested to equip learning facilitators with information to support decision making and respond to learning styles of their students. However, pedagogical implications of this information are not explored. Table IV only shows aggregated results, but the data warehouse design proposed in this article could allow drill down facilities to allow course facilitators to see the measures for their specific course. Examples are given below:

For Productivity 210 a significant correlation was shown between the visual-verbal dimension and quizzes. This served as indication to the lecturer that the way in which the questions are asked caused the visual learners to spend more time to answer quizzes, which prompts the lecturer to critically consider the way in which questions are set. The same lecturer found a significant correlation between semester mark per student and the "MyGrades" tool. All assignment and test results were published on "MyGrades" from the beginning of the semester. This served as motivation for students who accessed this information regularly and also made the rectification of faulty results possible.

\section{Conclusion}

"Advances in technology have dramatically enhanced the level of productivity and efficiency of Higher Education Institutions (HEIs) ... However, despite the availability of powerful computers, advanced network and communication infrastructure and sophisticated software applications, university decision makers, still lack access to the critical information necessary for informed decision making” (Guan et al., 2002).

Many facilitators of learning draw manually the same type of queries from CMS data for purposes of action research. On the other hand, more and more HEI infrastructure providers create data warehouses to support many kinds of decision-making. It is possible and valuable to follow a business intelligence approach to facilitate the queries drawn by individual action researchers from course management systems (CMSs). Much of the value still remains undiscovered. An intelligent educational system could enable the 
combination and comparing of results within and between curricula. The cases presented in this article are based on a prototype data warehouse. The expectation exists, however, that as the technology on which CMSs, as well as business intelligence tools are built evolves, the creation of fullscale business intelligence will become more feasible and scalable.

Figure 1 Business intelligence framework

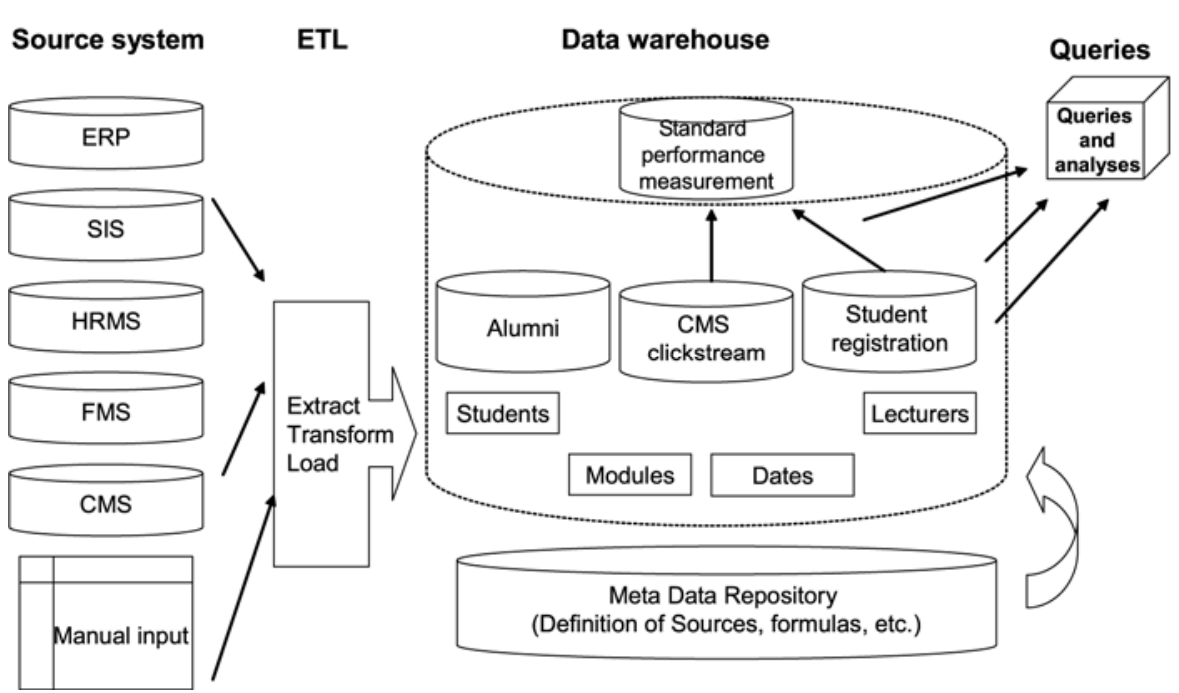

Figure 2 Click stream data mart

\begin{tabular}{|c|c|c|}
\hline Student dimension & \multirow{4}{*}{$\begin{array}{l}\text { Clickstream Log Fact Table } \\
\text { Student key (FK) } \\
\text { Module key (FK) } \\
\text { Date key (FK) } \\
\text { Time of day key (FK) } \\
\text { Duration of page visit } \\
\text { Page key (FK) }\end{array}$} & Date dimension \\
\hline \multirow[t]{3}{*}{$\begin{array}{l}\text { Student key (PK) } \\
\text { Student number } \\
\text { Date of birth } \\
\text { Gender } \\
\text { Race } \\
\text { Felder ILS Active-Reflective } \\
\text { Felder ILS Sensory-Intuitive } \\
\text { Felder ILS Visual-Verbal } \\
\text { Felder ILS Sequentially-Globally }\end{array}$} & & $\begin{array}{l}\text { Date key (FK) } \\
\text { Calendar year } \\
\text { Calendar week } \\
\text { Day of week } \\
\text { Holiday } \\
\text { Test week } \\
\text { Semester } \\
\text { Semester week } \\
\end{array}$ \\
\hline & & Time of day dimension \\
\hline & & $\begin{array}{l}\text { Time of day key (PK) } \\
\text { Hour of day } \\
\text { Computer lab open }\end{array}$ \\
\hline \multirow{2}{*}{$\begin{array}{l}\text { Module key (PK) } \\
\text { Host department } \\
\text { Description of module } \\
\text { Lecturer (FK) } \\
\text { CMS supported indicator } \\
\text { Year presented } \\
\text { Semester presented }\end{array}$} & & Page dimension \\
\hline & & $\begin{array}{l}\text { Page key (PK) } \\
\text { Page description } \\
\text { Type of page description } \\
\text { Type of page code }\end{array}$ \\
\hline
\end{tabular}


Figure 3 Aggregate click stream data mart

\begin{tabular}{|c|c|c|}
\hline \multirow[b]{3}{*}{ Student dimension } & \multirow{11}{*}{$\begin{array}{l}\text { Aggregate clickstream fact table } \\
\text { Aggregate clickstream key (PK) } \\
\text { Exam date key } \\
\text { Student key } \\
\text { Module key } \\
\text { Number of articles read } \\
\text { Number of articles posted } \\
\text { Number of assignment logs } \\
\text { Number of calendar logs } \\
\text { Number of homepage logs } \\
\text { Number of mygrades logs } \\
\text { Number of notes logs } \\
\text { Number of quiz logs } \\
\text { Number of tool pages logs } \\
\text { Progress mark } \\
\text { Exam mark } \\
\text { Final mark }\end{array}$} & Results dimension \\
\hline & & \multirow{4}{*}{$\begin{array}{l}\text { Student key (FK) } \\
\text { Module key (FK) } \\
\text { Semester mark } \\
\text { Examination mark } \\
\text { Final mark } \\
\end{array}$} \\
\hline & & \\
\hline \multirow{8}{*}{$\begin{array}{l}\text { Student key (PK) } \\
\text { Student number } \\
\text { Date of birth } \\
\text { Gender } \\
\text { Race } \\
\text { M-Score } \\
\text { Felder ILS Active-Reflective } \\
\text { Felder ILS Sensory-Intuitive } \\
\text { Felder ILS Visual-Verbal } \\
\text { Felder ILS Sequentially-Globally }\end{array}$} & & \\
\hline & & \\
\hline & & Module dimension \\
\hline & & Module key (PK) \\
\hline & & Host department \\
\hline & & Description of module \\
\hline & & Lecturer (FK) \\
\hline & & $\begin{array}{l}\text { Year presented } \\
\text { Semester presented }\end{array}$ \\
\hline
\end{tabular}

Table I Studies that measured the correlation between CMS activity and learning styles

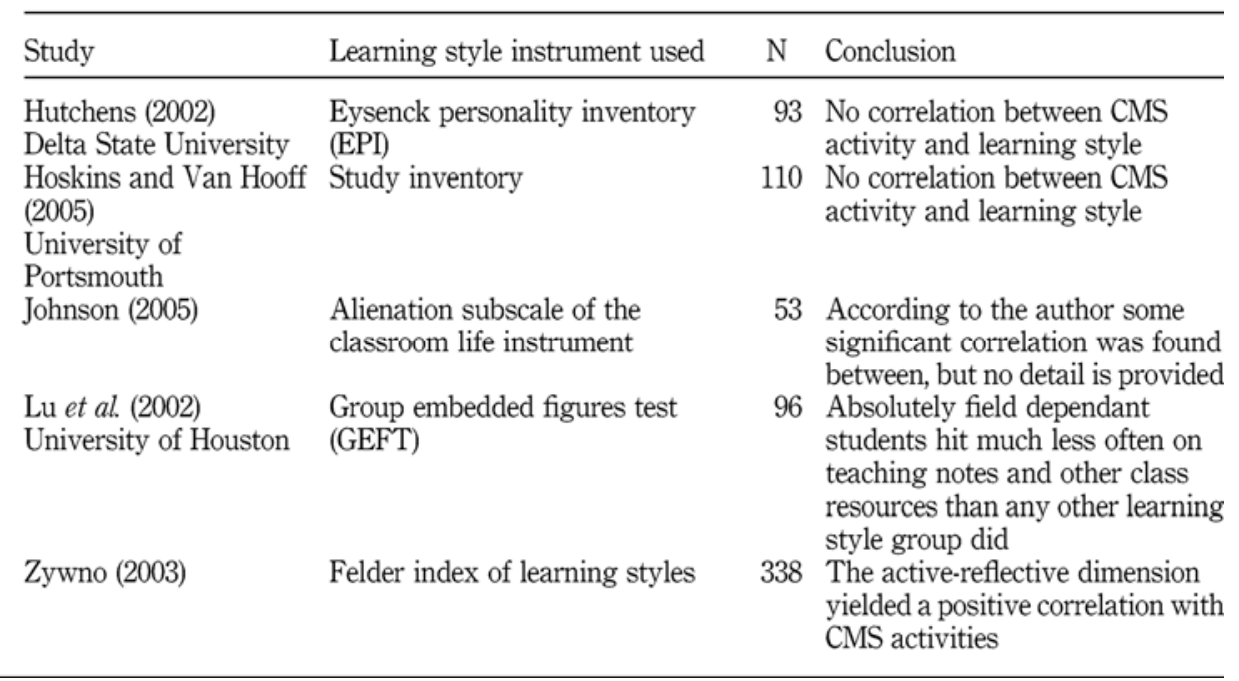


Table II Extraction of source data to data mart map

\begin{tabular}{|c|c|c|c|c|c|c|}
\hline \multirow[b]{2}{*}{ Attribute } & \multicolumn{3}{|c|}{$\begin{array}{l}\text { Transactional } \\
\text { system }\end{array}$} & \multicolumn{3}{|c|}{ Manual input } \\
\hline & SIS & CMS & ERP & Calen-dar & Felder ILS & WebCT manual \\
\hline Student number & $x$ & $x$ & $x$ & & & \\
\hline Date of birth & $x$ & & & & & \\
\hline Gender & $x$ & & & & & \\
\hline Race & $x$ & & & & & \\
\hline M-Score & $x$ & & & & & \\
\hline Time of day & & $x$ & & $x$ & & \\
\hline Hour of day & & $x$ & & $x$ & & \\
\hline Computer lab open & & & & $x$ & & \\
\hline Page description & & & & & & $x$ \\
\hline Type of page & & $x$ & & & & $x$ \\
\hline Calendar year & & & & $x$ & & \\
\hline Calendar week & & & & $x$ & & \\
\hline Day of week & & & & $x$ & & \\
\hline Holiday & & & & $x$ & & \\
\hline Test week & & & & $x$ & & \\
\hline Semester & & & & $x$ & & \\
\hline Semester week & & & & $x$ & & \\
\hline Description of module & & & & $x$ & & \\
\hline Lecturer & & & & $x$ & & \\
\hline CMS supported indicator & & $x$ & & & & \\
\hline Year presented & $x$ & $x$ & & & & \\
\hline Semester presented & $x$ & $x$ & & & & \\
\hline Felder ILS (active-reflective) & & & & & $x$ & \\
\hline Felder ILS 2 (sensor-intuitive) & & & & & $x$ & \\
\hline Felder ILS 3 (visual-verbal) & & & & & $x$ & \\
\hline Felder ILS 4 (sequential-global) & & & & & $x$ & \\
\hline Semester mark & $x$ & & & & & \\
\hline Examination mark & $x$ & & & & & \\
\hline Final mark & $x$ & & & & & \\
\hline
\end{tabular}

Table III Felder ILS results amongst engineering students

\begin{tabular}{|c|c|c|c|c|c|c|c|c|c|}
\hline Study & $\mathrm{N}$ & $\begin{array}{c}\text { Active } \\
(\%)\end{array}$ & $\begin{array}{l}\text { Refl. } \\
(\%)\end{array}$ & $\begin{array}{c}\text { Sen-sing } \\
(\%)\end{array}$ & $\begin{array}{c}\text { In-tuitve } \\
(\%)\end{array}$ & $\begin{array}{c}\text { Visual } \\
(\%)\end{array}$ & $\begin{array}{c}\text { Verbal } \\
(\%)\end{array}$ & $\begin{array}{c}\text { Sequation } \\
(\%)\end{array}$ & $\begin{array}{c}\text { Global } \\
(\%)\end{array}$ \\
\hline University of Pretoria, 2005 (this study) & 482 & 56 & 44 & 61 & 39 & 87 & 13 & 52 & 48 \\
\hline University of Western, Ontario, Canada & 858 & 69 & 31 & 59 & 41 & 80 & 20 & 67 & 33 \\
\hline University of Michigan, Michigan & 143 & 67 & 33 & 57 & 43 & 69 & 31 & 71 & 29 \\
\hline Tulane University, Alabama & 255 & 60 & 40 & 58 & 42 & 85 & 15 & 50 & 50 \\
\hline University of Technology, Kingston, Jamaica & 33 & 55 & 45 & 60 & 40 & 70 & 30 & 55 & 45 \\
\hline University of Sao Paulo, Sao Paulo, Brazil & 351 & 60 & 40 & 74 & 26 & 79 & 21 & 50 & 50 \\
\hline Ryerson, Canada, 2000-2002 & 338 & 61 & 39 & 65 & 35 & 88 & 12 & 63 & 37 \\
\hline
\end{tabular}

Ryerson, Canada, 2000-2002

Source: Felder and Spurlin (2005) 
Table IV Number of modules that show a significant correlation $(p<0.05)$ between CMS tool frequency and learning style or performance indices

\begin{tabular}{|c|c|c|c|c|c|c|c|c|c|c|c|c|}
\hline & CMS tool & $\begin{array}{c}\text { Home } \\
\text { page }\end{array}$ & $\begin{array}{l}\text { Discussions } \\
\text { read }\end{array}$ & $\begin{array}{l}\text { Discussions } \\
\text { write }\end{array}$ & E-mail & Calendar & - Content & $\begin{array}{c}\text { My } \\
\text { grades }\end{array}$ & Assignment & Quiz & $\begin{array}{c}\text { Organizer } \\
\text { pages }\end{array}$ & Total \\
\hline & $\begin{array}{l}\text { Number of modules under } \\
\text { investigation for which this tool is } \\
\text { used }\end{array}$ & 47 & 21 & 20 & 10 & 15 & 32 & 39 & 34 & 9 & 11 & 47 \\
\hline & Felder ILS: reflective & 6 & 5 & 0 & 1 & 5 & 1 & 4 & 3 & 1 & 2 & 8 \\
\hline & Felder ILS: active & 0 & 0 & 0 & 0 & 0 & 0 & 0 & 0 & 0 & 0 & \\
\hline & Felder ILS: intuitive & 3 & 4 & 0 & 0 & 1 & 5 & 1 & 1 & 1 & 0 & 6 \\
\hline Table IV. & Felder ILS: sensing & 0 & 0 & 2 & 0 & 0 & 0 & 0 & 0 & 0 & 0 & 6 \\
\hline Number of modules that & Felder ILS: visual & 1 & 1 & 2 & 0 & 1 & 1 & 1 & 1 & 1 & 0 & 2 \\
\hline show a significant & Felder ILS: verbal & 1 & 1 & 2 & 0 & 1 & 1 & 1 & 1 & 1 & 0 & \\
\hline correlation $(p<0.05)$ & Felder ILS: sequential & 5 & 0 & 1 & 0 & 1 & 0 & 0 & 0 & 1 & 0 & 4 \\
\hline between CMS tool & Felder ILS: global & 0 & 2 & 0 & 0 & 0 & 2 & 0 & 0 & 0 & 0 & 0 \\
\hline frequency and learning & Results: school (M) & 12 & 0 & 2 & 0 & 0 & 8 & 2 & 0 & 0 & 3 & \\
\hline style or performance & Results: semester mark & 13 & 4 & 2 & 3 & 6 & 6 & 9 & 6 & 6 & 0 & 9 \\
\hline indices & Results: examination & 9 & 2 & 1 & 2 & 2 & 4 & 3 & 4 & 4 & 0 & 8 \\
\hline
\end{tabular}

\section{References}

Akeroyd, J. (2005), "Information management and e-learning, some perspectives", Aslib Proceedings: New Information Perspectives, Vol. 52 No.2, pp.157-67.

Alstete, J.W., Beutell, N.J. (2004), "Performance indicators in online distance learning courses: a study of management education", Quality Assurance in Education, Vol. 12 No.1, pp.6-14.

Bongey, S.B., Cizadio, G., Kainbach, L. (2005), "Using a course management system (cms) to meet the challenges of large lecture classes", Campus-Wide Information Systems, Vol. 22 No.5, pp.252-62.

Coffield, F., Mosely, D., Hall, E., Ecclestone, K. (2004), Should We be Using Learning Styles? What Research Has to Say About Practice, technical report, Learning and Skills Research Centre, Learning and Skills Development Agency, Regent, London.

Felder, R., Spurlin, J. (2005), "Applications, reliability and validity of the index of learning styles", International Journal of Engineering Education, Vol. 21 No.1, pp.10312.

Felder, R.M., Silverman, L.K. (1988), "Learning and teaching styles in engineering education", Engineering Education, Vol. 78 No.7, pp.674-81.

Green, S.M., Weaver, M., Voegeli, D., Fitzsimmons, D., Knowles, J., Harrison, M., Shephard, K. (2006), "The development and evaluation of the use of a virtual learning environment (blackboard 5) to support learning of pre-qualifying nursing students undertaking a human anatomy and physiology module", Nurse Education Today. 
Guan, J., Nunez, W., Welsh, J.F. (2002), "Institutional strategy and information support: the role of data warehousing in higher education", Campus-Wide Information Systems, Vol. 19 No.5, pp.168-74.

Heise, D. (2005), Educause Higher Education Data Warehouse Directory, available at: dheise.andrews.edu/dw/DWData.html (accessed 26 May 2005).

Hoskins, S.L., Hooff, J.C.V. (2005), "Motivation and ability: which students use online learning and what influence does it have on their achievement?", British Journal of Educational Technology, Vol. 36 No.2, pp.177-92.

Hutchens, S.A. (2002), "Success in technology-assisted courses: an investigation of the effects of student personality traits”, Proceedings of the International Conference on Computers in Education, 3-6 December, Auckland, New Zealand.

Johnson, G.M. (2005), "Student alienation, academic achievement, and WebCT use", Educational Technology and Society, Vol. 8 No.5, pp.179-89.

Kimball, R., Ross, M. (2002), The Data Warehouse Toolkit, 2nd ed., John Wiley and Sons, New York, NY.

Lu, J., Yu, C.S., Lui, C. (2003), "Learning style, learning patterns, and learning performance in a WebCT-based mis course", Information and Management, Vol. 40 No.6.

Lundy, J., Harris, K. (2001), E-learning Suites Emerge: Prices Down, Functionality Up, Gartner Research Group, Stamford, CT, Research Note M-13-6326.

Oracle (2001), Oracle CRM for higher education. Higher Ed Solution 800.633.0584 x 8730, Oracle Corporation, Redwood Shores, CA.

Van Zwanenberg, N., Wilkonson, L.J., Anderson, A. (2000), "Felder and Silverman's index of learning styles and honey and mumford's learning styles questionnaire: how do they compare and do they predict academic performance?", Educational Psycology, Vol. 20 No.3, pp.365-80.

Whitten, J.L., Bently, L.D., Dittman, K.C. (2004), Sytems Analysis and Design Methods, 5th ed., McGraw Hill, New York, NY.

Wikipedia, W. (2005), The Free Encyclopedia, available at: http://0en.wikipedia.org.innopac.up.ac.za:80 (accessed 28 September 2005).

Wikipedia, W. (2006), The Free Encyclopedia, available at: http://0en.wikipedia.org.innopac.up.ac.za:80 (accessed 17 July 2006). 
ZuberSkerrit, O. (1992), Professional Development In Higher Education: A Theoretical Framework for Action Research, Kogan Page, London.

Zywno, M.S. (2003), “Student learning styles, web use patterns and attitudes toward hypermedia-enhanced instruction”, paper presented at the ASEE/IEEE Frontiers in Education Conference, (Session S1D), 5-8 November, Boulder, CO.

\section{Corresponding author}

Liezl van Dyk can be contacted at: Lvd@sun.ac.za 